\title{
Phytotoxic Evaluation of Phytosynthesized Silver Nanoparticles on Lettuce
}

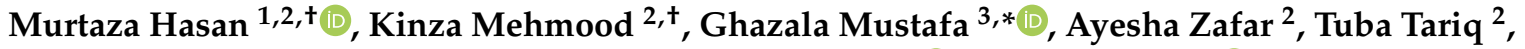 \\ Shahbaz Gul Hassan ${ }^{4}$, Suraj Loomba ${ }^{5}$, Muhammad Zia ${ }^{6}$ (D), Abeer Mazher ${ }^{7}$, Nasir Mahmood ${ }^{5, *(D)}$ \\ and Xugang Shu ${ }^{1, *}$
}

1 College of Chemistry and Chemical Engineering, Zhongkai University of Agriculture and Engineering, Guangzhou 510225, China; murtaza@zhku.edu.cn

2 Department of Biotechnology, The Institute of Biochemistry, Biotechnology and Bioinformatics, The Islamia University of Bahawalpur, Bahawalpur 63100, Pakistan; kinzamehmood213@gmail.com (K.M.); ayeshazafar510@gmail.com (A.Z.); tubatariq222@gmail.com (T.T.)

3 Department of Plant Sciences, Quaid-i-Azam University, Islamabad 45320, Pakistan

4 College of Information Science and Engineering, Zhongkai University of Agriculture and Engineering, Guangzhou 510225, China; mhasan387@cau.edu.cn

5 School of Engineering, Royal Melbourne Institute of Technology (RMIT) University Melbourne, 124 La Trobe Street, Melbourne, VIC 3001, Australia; suraj.loomba@rmit.edu.au

6 Department of Biotechnology, Quaid-i-Azam University, Islamabad 45320, Pakistan; ziachaudhary@gmail.com

7 CSIRO Mineral Resources, Deep Earth Imaging-Future Science Platform, Kensington, WA 6151, Australia; abeer.mazher@csiro.au

* Correspondence: mghazala@qau.edu.pk (G.M.); nasir.mahmood@rmit.edu.au (N.M.);xgshu@21cn.com (X.S.)

+ These two authors equally contributed.

check for updates

Citation: Hasan, M.; Mehmood, K.; Mustafa, G.; Zafar, A.; Tariq, T.; Hassan, S.G.; Loomba, S.; Zia, M.; Mazher, A.; Mahmood, N.; et al. Phytotoxic Evaluation of Phytosynthesized Silver Nanoparticles on Lettuce. Coatings 2021, 11, 225. https://doi.org/ $10.3390 /$ coatings 11020225

Received: 12 January 2021

Accepted: 9 February 2021

Published: 13 February 2021

Publisher's Note: MDPI stays neutral with regard to jurisdictional claims in published maps and institutional affiliations.

Copyright: (c) 2021 by the authors Licensee MDPI, Basel, Switzerland. This article is an open access article distributed under the terms and conditions of the Creative Commons Attribution (CC BY) license (https:// creativecommons.org/licenses/by/ $4.0 /)$.
Abstract: The increasing metal release into the environment warrants investigating their impact on plants, which are cornerstones of ecosystems. Here, Lactuca sativa L. (lettuce) seedlings were exposed hydroponically to different concentrations of silver ions and nanoparticles (Ag NPs) for 25 days to evaluate their impact on plant growth. Seedlings taking $\mathrm{Ag}^{+}$ions showed an increment of $18 \%$ in total phenolic content and $12 \%$ in total flavonoid content, whereas under Ag NPs, $7 \%$ free radical scavenging activity, $12 \%$ total phenolic contents (TPC), and 10\% total reducing power are increased. An increase in 31\% shoot length, 25\% chlorophyll, 11\% carbohydrate, and $16 \%$ protein content of the lettuce plant is observed in response to $\mathrm{Ag}$ NPs, while silver nitrate $\left(\mathrm{AgNO}_{3}\right)$ has a reduced $40 \%$ growth. The lettuce plant was most susceptible to toxic effects of $\mathrm{Ag}+$ ions at a lower concentration, i.e., $0.01 \mathrm{mg} / \mathrm{L}$, while $\mathrm{Ag}$ NPs showed less toxicity, only when higher concentrations $>100 \mathrm{mg} / \mathrm{L}$ were applied. Further, biomolecules other than antioxidant enzymes showed higher phytotoxicity for $\mathrm{Ag}^{+}$ ions, followed by Ag NPs with the concentration of 25, 50, and $100 \mathrm{mg} / \mathrm{L}$ compared to the control. Thus, moderate concentrations of Ag NPs have a stimulatory effect on seedling growth, while higher concentrations induced inhibitory effects due to the release of $\mathrm{Ag}^{+}$ions. These results suggest that optimum metallic contents are desirable for the healthier growth of plants in a controlled way.

Keywords: nanoecotoxicology; plant health; seedling; phytotoxicity; ultra-efficient

\section{Introduction}

The large-scale production of nanomaterials and their use for various agronomic applications, such as nano pesticides and nano fertilizers, as well as controlling the pathogens can also impact the ecosystem. In addition, their interaction with plants needs to be investigated [1-3]. Moreover, tons of waste from the industry dealing with the synthesis of a variety of nanomaterials is added to the aquatic, terrestrial, and atmospheric environments that directly and indirectly impact the plants [4,5]. Plants are the primary producer of the ecosystem and play a vital role in cycling the food chain for all living organisms. Therefore, 
understanding the impact of nanoparticles on plant growth and development is crucial for the evaluation of potential environmental risks on food safety and human health imposed by NPs [6]. Recently, few researchers have explained the process of transformation of NPs in the soil-plant system or hydroponic culture to plants that have an effect on plant metabolism [7,8]. The detailed process of uptake, translocation, and accumulation of Ag NPs and iron in micro and nano size in plants, as well as their phytotoxicity on plants at morphological, physiological, cellular, and molecular levels is still poorly explained. Previously, the effects of NPs have been studied in rice and zero to low toxicity was found at germination stages [9]. However, the influence of these NPs in higher plants is not fully explored yet and a controlled testimonial study needs to be done under different parameters such as the concentration/size of particles, age of plant, and experimental conditions such as the method and duration of exposure. It is found that Ag NPs have a positive role in the growth of few plants such as Brasicca juncea L. Czern. [10], Phaseolus vulgaris L. [11], and Zea mays L. [12], while a negative effect on the root growth in various plants (Linum usitatissimum L. and Hordeum vulgare L.) upon higher accumulation [13,14]. The toxicity of Ag NPs is due to the bioaccumulation of silver ions $\left(\mathrm{Ag}^{+}\right.$ions) that lower the production of chlorophyll, ultimately reducing the photosynthesis and impacting the cell growth $[15,16]$. Moreover, there are studies which offer evidence that NPs contribute more to their toxicity than the $\mathrm{Ag}^{+}$dissociation $[17,18]$. To date, many efforts have been put forward to explore the impact of metallic NPs on plant growth and life, especially metals such as silver, since the production of Ag NPs will reach 1216 tons by 2020 and $614.4 \mathrm{mg} / \mathrm{kg}$ will be deposited in the sediments $[19,20]$. With their impact on the biological system at a molecular level not fully understood, it is important to strengthen the knowledge at a molecular level and explore the mechanisms that mediate the effect of Ag NPs in plants. The lettuce plant can be a good experimental plant as it is commonly used as a model organism in phytotoxicity studies [21,22]. In addition, it has a fast growth rate which makes it easy to see the effects. There are many reports on physical and chemical methods of nanoparticles synthesis $[23,24]$ but phytosynthesized nanoparticles and their impact on plants are rarely studied [25-28].

The present study aims to assess the effect of phytosynthesized Ag NPs and $\mathrm{Ag}^{+}$ion $\left(\mathrm{AgNO}_{3}\right)$ at the seedling stage of lettuce, regardless of previous studies where the NPs impact were mainly investigated at the seed germination stage. We have evaluated the influence of Ag NPs and ions on the growth of lettuce plants in hydroponics. Representative parameters such as root-shoot length, fresh weight, and biochemical parameters such as chlorophyll content, sugar, nitrate protein content, and antioxidant activities were investigated to understand the plant's defence and response to abiotic stress caused by Ag $\mathrm{NPs}$ and $\mathrm{AgNO}_{3}$.

\section{Materials and Methods}

\subsection{Equipment}

The morphology and size were determined using transmission electron microscope (TEM) images by the JEM 2100 equipment (JEOL, Tokyo, Japan). The UV-vis spectrophotometric analysis was used to determine the synthesis of nanoparticles and the nitrate content was determined by measuring the absorbance of synthesized Ag NPs, as well as the total amount of nitrate in the respective solution at room temperature. A simple compound microscope was used to analyze the anatomical parameters of the root, stem, and leaf by taking freshly cut thin slices of each part, followed by staining and monitoring under a microscope at $1500 \mathrm{X}$ at room temperature. A digital camera captured and recorded the anatomical changes. Transmission electron microscopy (JEM-2100 TEM) was performed to determine the morphology and size of synthesized Ag NPs. Calorimetry was performed to evaluate the sugar content at room temperature in the extracted solution. 


\subsection{Biosynthesis of Silver Nanoparticles}

The Ag NPs were synthesized using the Fagonia cretica L. plant extract based on our previous work [18]. Initially, a $0.1 \mathrm{M}$ aqueous solution of $\mathrm{AgNO}_{3}$ was prepared and mixed with the plant extract at a 5:1 ratio, respectively. The mixture was stirred with a magnetic stirrer (150 rpm) at $50{ }^{\circ} \mathrm{C}$ for $15-120 \mathrm{~min}$. The colour change in the reaction mixture was recorded through a visual observation. The bio reduction of $\mathrm{Ag}$ ions in the aqueous solution was periodically monitored by UV-vis spectroscopy (Bahawalpur, Pakistan). On completion of the reaction, the product was collected using a centrifuge (20 min at $6000 \mathrm{rpm}$ ). The supernatant was saved in separate falcon tubes and kept at $4{ }^{\circ} \mathrm{C}$ for high performance liquid chromatography (HPLC, Bahawalpur, Pakistan). Note: Various concentrations of the $\mathrm{AgNO}_{3}$ aqueous solution $(0.5,1$, and $2 \mathrm{mM})$ and plant extract $(10,20$, and $40 \mathrm{~mL})$ were used to determine their impact on the growth of Ag NPs. The morphology and size were determined using transmission electron microscope (TEM) images by JEOL JEM 2100. The stable suspensions of different concentrations of Ag NPs were prepared in water for further use at all stages.

\subsection{Application of Silver Nanoparticles and Silver Nitrate}

The seeds were hand sown in a seedling tray containing the coconut peat medium, a porous organic peat mainly consisting of holocellulose and lignin content. Therefore, this establishes strong and healthy root systems, as well as increases the absorption of water and oxygen required for healthy plant growth. An adequate amount of water was sprinkled over the organic medium, as shown in Figure S2. The seeds started germination after a week. To ensure maximum germination, the organic medium must not run dry and should be sprinkled with water every day according to the requirements (Figure S3). Carefully without tugging, the individual seedlings were taken from their cells to the net pots, while the net pots were placed in containers containing hydroponic nutrients and water (Figures S4 and S5). Six uniform seedlings were transferred to net pots. Each net pot was carefully placed in a separate plastic container which acts as a nutrient reservoir. Plastic containers were filled with $1000 \mathrm{~mL}$ of Hoagland's solution. Lettuce seedlings were labelled as five test groups, i.e., the control group, 100, 50, $25 \mathrm{mg} / \mathrm{L} \mathrm{Ag} \mathrm{NPs} \mathrm{and} \mathrm{AgNO}_{3}$. After transferring the net pots to nutrient reservoirs, five tests groups were labelled. Each group was performed in triplets and supplied daily to test the plantlets with $12 \mathrm{~mL}$ of the Ag NPs solution in different concentrations. The AgNPs solutions were employed continuously for 25 days along with the control and an $\mathrm{AgNO}_{3}$ concentration of $0.01 \mathrm{M}$. All the plants were kept in an open atmosphere and maintained on $14 \mathrm{~h} \mathrm{light} / 10 \mathrm{~h}$ dark cycle at $\sim 22{ }^{\circ} \mathrm{C}$. Afterwards, the properly labelled containers were continuously kept under stress until harvesting (Figures S6 and S7).

\subsection{Extract Preparation and Nitrate Content Determination}

The plant nitrate contents were determined by the sulfosalicylic acid method, using potassium nitrate $\left(\mathrm{KNO}_{3}\right)$ as a standard. Fresh lettuce leaves $(0.3 \mathrm{~g})$ were added in the test tube, sealed with a plastic wrap, and then placed in boiling water for $30 \mathrm{~min}$. Finally, the lettuce leaf extract was filtered and the filtrate was used for further experiments. The nitrate content was measured using a UV-vis spectrophotometer at $410 \mathrm{~nm}$.

\subsection{Sugar Content Determination}

Initially, the lettuce extract was dissolved in acetone and $80 \%$ ethanol to extract the interfering pigments and the soluble sugar content from the sample, respectively by spinning at $7000 \times g$. The homogenate was centrifuged at $7000 \times g$ for $10 \mathrm{~min}$ and the supernatant was analysed by Anthrone calorimetry for the soluble sugar method [29].

\subsection{Protein Content Determination}

One gram of dried tissue powder was suspended in $0.8 \mathrm{~mL}$ ice-cold sodium dodecyl sulphate (SDS) phenol buffer (0.1 M Tris-HCL pH 8.0, 30\% sucrose, $2 \%$ SDS, $2 \%$ dithio- 
threitol (DTT) with an equal volume of Tris-buffered phenol with a $\mathrm{pH}$ 8.0). The mixture was then shaken and centrifuged at $10,500 \times g$ for $5 \mathrm{~min}$ at $4{ }^{\circ} \mathrm{C}$. The obtained phenolic phase containing proteins was precipitated overnight at $-20^{\circ} \mathrm{C}$ by adding $5 \%$ of $0.1 \mathrm{M}$ ammonium acetate in methanol $(v / v)$ and then centrifuged at $7000 \times \mathrm{g}$ for $15 \mathrm{~min}$ at $4{ }^{\circ} \mathrm{C}$. The obtained pallet was washed thrice with $80 \%$ acetone. Finally, the dried sample was dissolved in a buffer containing $7 \mathrm{M}$ urea and $2 \mathrm{M}$ thiourea. The protein concentration was measured with the Bradford assay using bovine Y-globulin as a standard [30].

\subsection{Statistical Analysis}

The collected data was analysed using Statistical Packages for Social Sciences (SPSS). The mean values obtained from the control and treatment groups were compared using One-way ANOVA in order to test the statistical significance across the group means at $0.001 \%, 0.01 \%, 1 \%$, and $5 \%$ significance level. This was followed by the Tukey-Kramer multiple comparison test to look for specific differences between pairs of groups. Results are presented as the mean \pm standard deviation and were observed for statistically significant differences at ${ }^{*}: p<0.05 ;^{* *}: p<0.01 ;^{* * *}: p<0.001{ }^{* * * *} p<0.0001$.

\section{Results}

\subsection{Synthesis and Characterization of $A g N P S$}

The overall synthesis process of Ag NPs and their impact on the chlorophyll content, phenolic content, and 2,2-diphenyl-1-picrylhydrazyl (DPPH) in the lettuce plant are shown schematically in Figure 1.

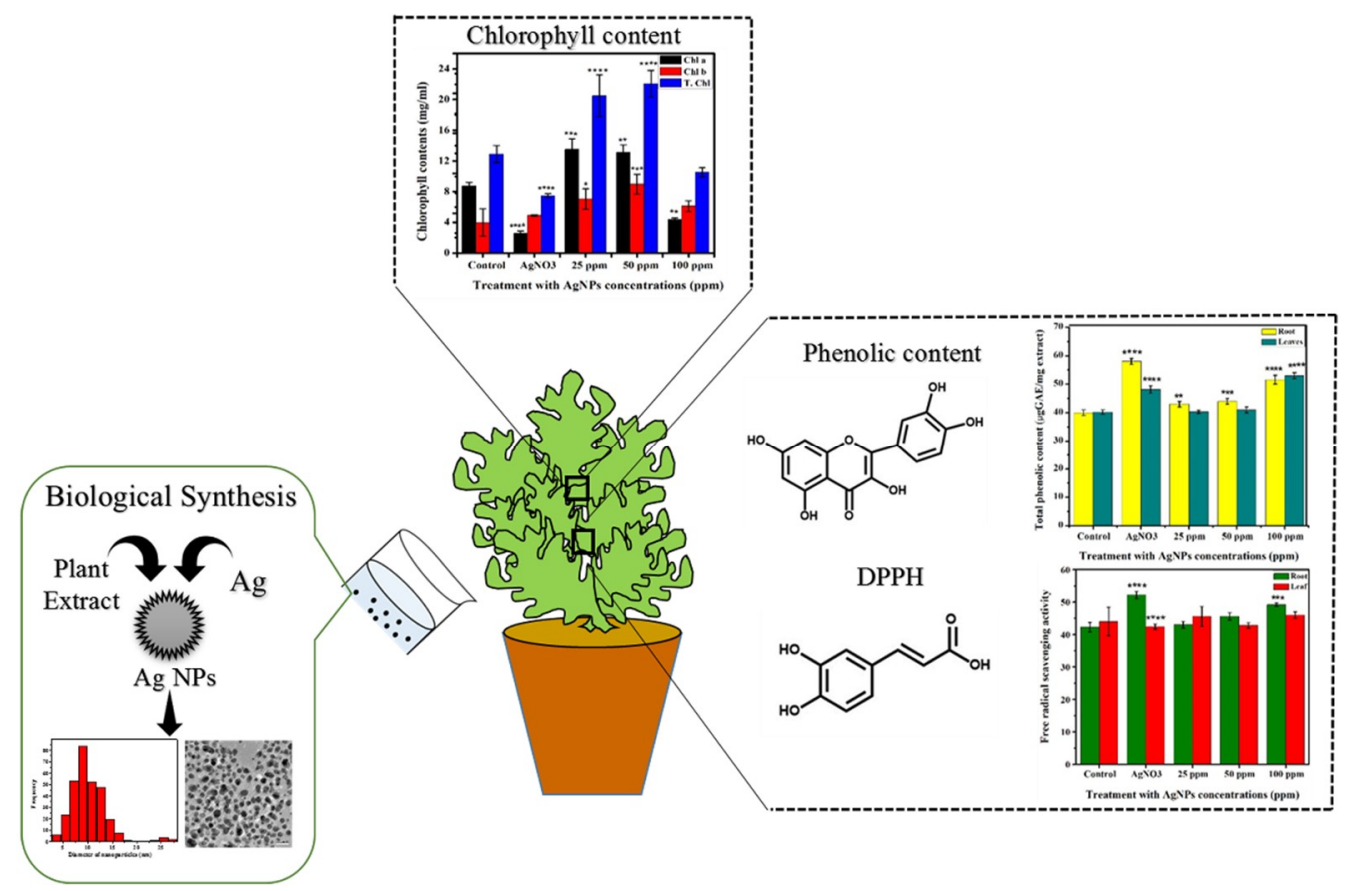

Figure 1. Schematic illustration of the green synthesis of Ag NPs, as well as morphological and biochemical characteristics of lettuce in response to metallic vs. ionic silver. The symbol of ${ }^{* * *},{ }^{* * *},{ }^{* * *}$ show that datasets are significantly different from one another.

Initially, the Ag NPs were examined by UV-vis, the appearance of an obvious peak at $440 \mathrm{~nm}$ due to the surface plasmonic effect of Ag NPs confirms their presence which was absent in the pure plant extract (Figure 2a). Therefore, TEM studies were conducted to observe the morphology and size of Ag NPs which suggested that particles are grown in a spherical shape having an average size of $12 \mathrm{~nm}$ (Figure $2 \mathrm{~b}$, the inset shows a histogram presenting the size distribution). However, the current results of the nanoparticles synthesis match the previous reports regarding the phytosynthesis of nanoparticles [31,32]. It is well 
known that particles less than $15 \mathrm{~nm}$ can easily diffuse into the cell and then their impact on cell metabolism can be observed [33,34].

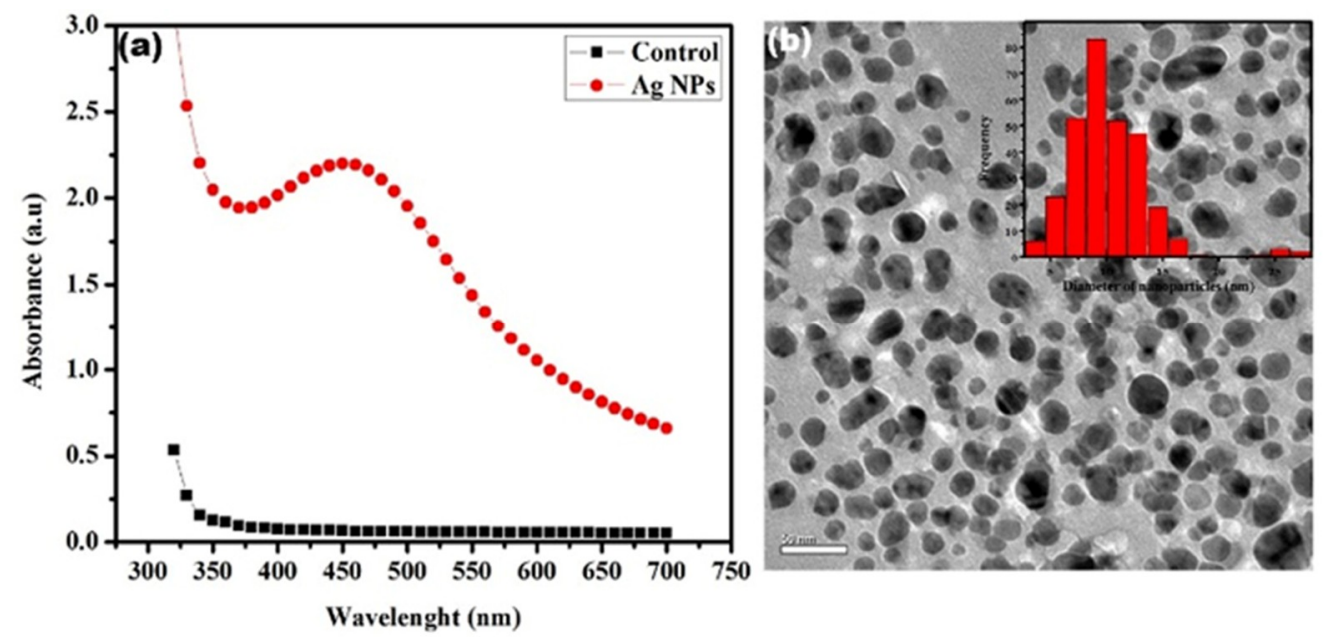

Figure 2. (a) Ultraviolet (UV)-visible spectra of $\mathrm{Ag} \mathrm{NPs}$ (red) and $\mathrm{AgNO}_{3}$ solution without the plant extract (black). (b) TEM image of Ag NPs (the insets show a histogram representing the Ag NPs size distribution.

After confirming the size of Ag NPs, these Ag NPs along with $\mathrm{Ag}^{+}$ions $\left(\mathrm{AgNO}_{3}\right)$ were given to the plants, as described in the Supporting Information (Figures S1-S7). The TEM analysis of Ag NPs in suspension is also carried out after a month (Figure S8), which shows the same results as the synthesis, confirming a high stability of Ag NPs suspension in water.

\subsection{Application of Silver Nanoparticles and Silver Nitrate on Lettuce}

Validating the presence of nanoparticles in different segments was performed using anatomical microscopic studies. These microscopic studies revealed the absorption and retention of the silver NP. The presence of the Ag NPs in the root, stem, and leaves were marked by yellow arrows (Figure 3a-c). The NPs had induced cell death at $100 \mathrm{ppm}$ of the concentration, while 25 and $50 \mathrm{ppm}$ were found to be safe and applicable on the lettuce as the apoptosis was observed by the anatomy results. Significant changes in the anatomy of the plant were observed in response to the Ag NPs compared to the control, which show the insertion of Ag NPs into the cells as particles not ions, as presented by the yellow arrows in Figure 3a,b.

The present work gives confirmation of previous reports by Harshiny et al. [35] that NPs remain mainly adhered to the roots (Figure $3 a-c)$. However, it was more interesting to observe the physiological effects of all three concentrations of NPs on the root, shoot length, and leaves surface area. The effect of Ag NPs and $\mathrm{Ag}^{+}$ions on both the root and shoot length is shown in Figure 4a-c. A significant reduction in the root length of the lettuce plant is observed in response to Ag NPs and ions compared to the control. A large reduction up to $36 \%$ in root length in response to $\mathrm{Ag}^{+}$ions was observed, while only $21 \%$, $17 \%$, and $19 \%$ reduction is observed for Ag NPs corresponding to its concentrations of 25, 50, and $100 \mathrm{ppm}$, respectively in regards to the control, as shown in Figure 4b. Overall, the least reduction in root length was observed at $50 \mathrm{ppm}$ (Figure $4 \mathrm{~b}$ ). These results are in accordance with earlier reported results on wheat growth regulation affected by different concentrations of Ag NPs [36].

Similarly, the impact of $\mathrm{Ag}$ NPs and $\mathrm{Ag}^{+}$ions on the growth of lettuce shoot is also observed, as shown in Figure 4c. A significant increase in $47 \%$ and $35 \%$ of the shoot length was observed in response to 25 and $50 \mathrm{ppm}$, respectively. However, upon treating with $100 \mathrm{ppm}$, the growth of the shoot is badly impacted and a significant reduction of $33 \%$ was observed in regards to the control. While, the $\mathrm{Ag}^{+}$ions show a $45 \%$ reduction in the shoot length, which show that the oxidative stress of $\mathrm{Ag}^{+}$ions can be observed with 
regards to the control in shoots and adversely impact their growth. Thus, $25 \mathrm{ppm}$ is the best concentration that at maximum stimulates the growth of the shoot, since a further increase in Ag NPs is less effective and even causes reduction as we reach 100 ppm, compared to the control. However, the mean concentration, i.e., 50 ppm provided a considerably optimized growth for both the root and shoot. Conclusively, 50 ppm was considered a better concentration for both the root and shoot (Figure 4c).

(a)

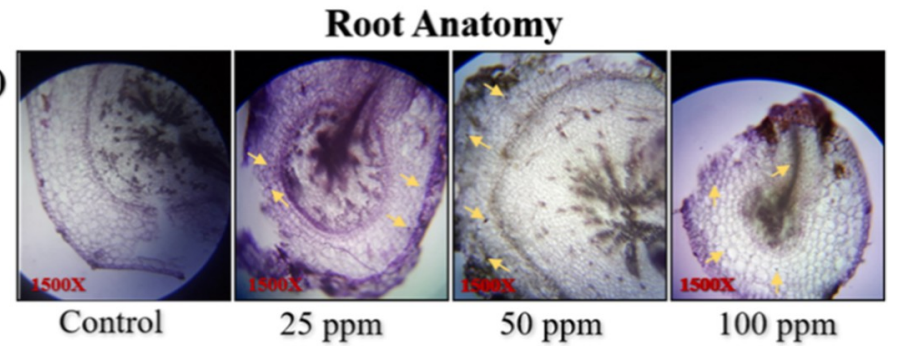

(b)

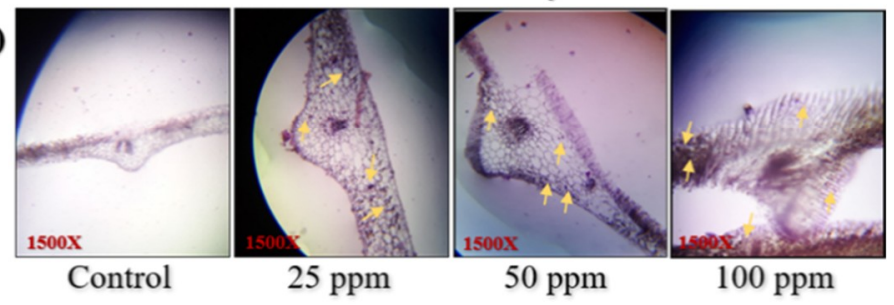

Stem Anatomy

(c)

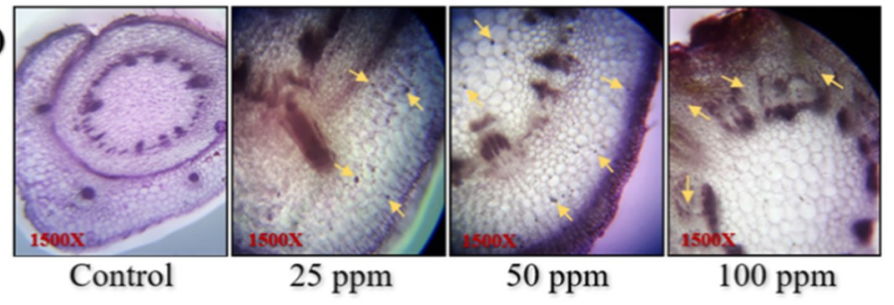

Figure 3. Anatomy of (a) root, (b) leaves, and (c) stem cells under different concentrations of Ag NPs. Arrows are pointing out the Ag particles. Images are recorded using a light compound microscope (Nikon 104, Japan) at a resolution of $1500 \mathrm{X}$ with the help of a 20 mega pixel digital camera.

However, the adverse impact of Ag NPs at a higher concentration ( $>50 \mathrm{ppm})$ and $\mathrm{Ag}^{+}$ions $\left(\mathrm{AgNO}_{3}\right)$ on the root and shoot length of the lettuce plant cannot be ignored. These outcomes show that the increase in the concentration of metallic particles to a certain limit can be tolerated by the plant and might even improve the plant growth up to a certain extent, however, higher concentrations of metal ions adversely affect the growth of plant $[37,38]$. In addition, the positive impact of the Ag NPs with a 50 ppm concentration on the morphological growth parameters of the lettuce plant with minimal toxicity can imply that a certain amount of metallic species is required for the healthier growth of plants. Looking at all the parameters, we conclusively considered $50 \mathrm{ppm}$ as the positive concentration that had improved the shoots length, protein content, nitrate content, chlorophyll content, etc., except for the roots.

The effects of Ag NPs and ions on the fresh and dry weight of lettuce are also observed, as shown in Figure 5a-c. Figure 5a shows the dense canopy and increased leaf surface area at a 25 and 50 ppm concentration of Ag NPs, whereas the reduced area can be observed at 100 ppm with regards to the control. An increase in the Ag NPs concentration up to 50 ppm results in the fresh and dry weight increase, however, the further increase in the Ag NPs concentration to 100 ppm results in the decrease in the fresh weight, as shown in Figure 5b. The Ag NPs with the concentrations of 25 and 50 ppm significantly increased the plant fresh weight by $9 \%$ and $14 \%$, while the dry weight increased by $15 \%$ and $21 \%$, 
respectively. Similar to the shoot and root growth, the higher concentration of $100 \mathrm{ppm}$ caused a reduction in fresh and dry weights by $34 \%$ and $21 \%$, respectively. The worse effects are found for $\mathrm{Ag}^{+}$ions which cause the reduction up to $59 \%$ and $47 \%$ in fresh and dry weights compared to the control (Figure $5 b$ ). Therefore, Ag NPs concentrations above $50 \mathrm{ppm}$ are proved detrimental for the seedling growth.

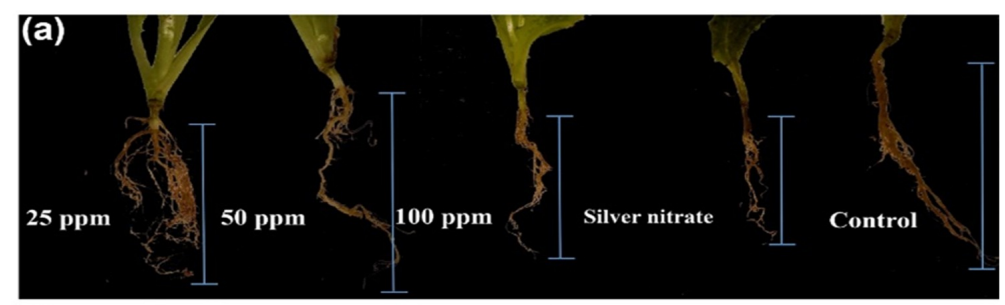

(b)

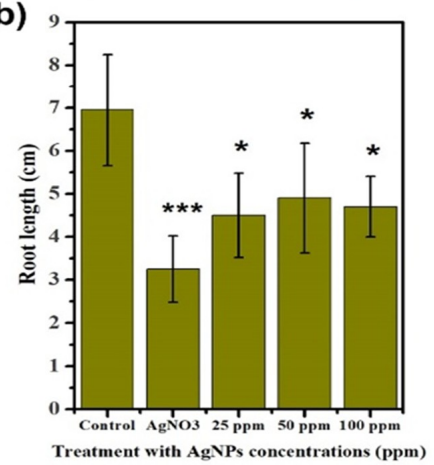

(c)

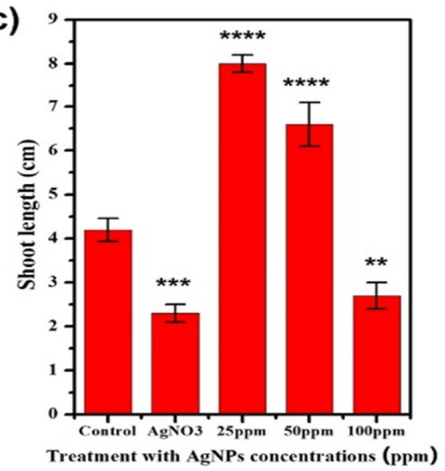

Figure 4. Effect of different concentrations of Ag NPs and $\mathrm{AgNO}_{3}(1 \mathrm{M})$ on root morphology (a) $\operatorname{root}(\mathbf{b})$ and shoot $(\mathbf{c})$ length of the lettuce plant. The symbol of ${ }^{* * *}, * * *, * * * *$ show that datasets are significantly different from one another.
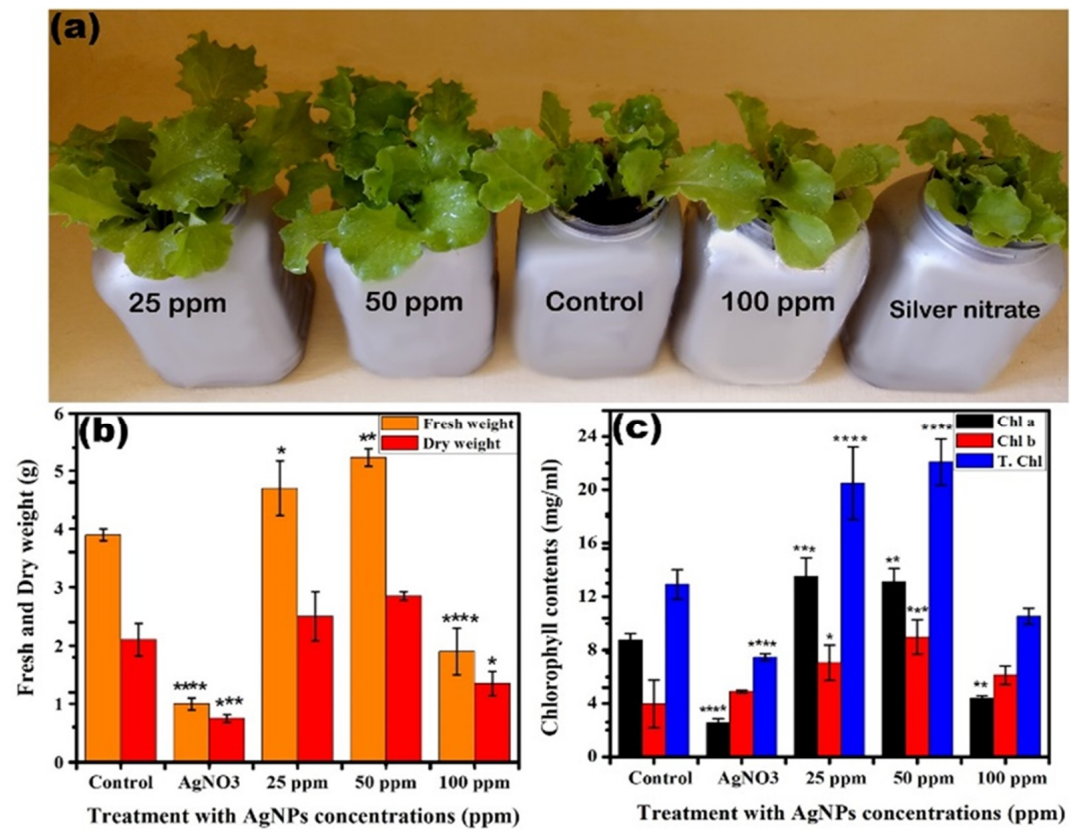

Figure 5. (a) Morphological and physiological study of different concentrations of Ag NPs and $1 \mathrm{M} \mathrm{AgNO}_{3}$ on the lettuce plant. (b) Fresh and dry weight of lettuce upon exposure to different concentrations of Ag NPs and $1 \mathrm{M} \mathrm{AgNO}_{3}$. (c) Chlorophyll a, chlorophyll b, and total chlorophyll of lettuce subjected to 25, 50, $100 \mathrm{ppm} \mathrm{Ag} \mathrm{NPs} \mathrm{and} 1 \mathrm{M} \mathrm{AgNO}_{3}$. The symbol of ${ }^{*}, * * * * *, * * * *$ show that datasets are significantly different from one another. 


\subsection{Impact of Silver Nanoparticles and Silver Nitrate on the Biochemistry of Lettuce}

Moreover, a positive impact is observed for Ag NPs on the chlorophyll content (chlorophyll a and b, total chlorophyll) of the lettuce plant compared to the control, while $\mathrm{Ag}^{+}$ ions brought negative effects, as shown in Figure 5c. Upon giving the dose of 25 and 50 ppm of Ag NPs, chlorophyll a and b increased by $21 \%$ and $28 \%$, respectively, compared to the control (Figure 5c). No significant difference was observed between 25 and $50 \mathrm{ppm}$. However, at a higher concentration of $100 \mathrm{ppm}$, a $32 \%$ decrease in chlorophyll a and $21 \%$ increase in chlorophyll $\mathrm{b}$ is observed. While, in the case of $\mathrm{AgNO}_{3}\left(\mathrm{Ag}^{+}\right.$ions), the chlorophyll b content increased by $10 \%$ and chlorophyll a decreased by $54 \%$ compared to the control. In fact, when the plants are under stress, the production of chlorophyll a is generally inhibited, which is compensated by producing more chlorophyll [39]. A similar trend was seen in the total chlorophyll content where 25 and $50 \mathrm{ppm}$ results in an increase of $22 \%$ and $26 \%$, respectively, while $100 \mathrm{ppm}$ and $\mathrm{Ag}^{+}$ions showed a decrease of $18 \%$ and $40 \%$ compared to the control (Figure $5 c$ ). The increase in total chlorophyll contents due to 25 and $50 \mathrm{ppm}$ is a result of the increase in chlorophyll a and b contents compared to the control, culminating in no net damage to chloroplasts by Ag NPs at these concentrations. The increase in the chlorophyll content clearly depicts that the chloroplasts efficiency has significantly increased by increasing the chlorophyll content with the Ag NPs treatment, a clear evidence that the chloroplast was not damaged, but rather had shown greater efficiency [40,41].

The effects of $\mathrm{Ag}$ NPs and $\mathrm{Ag}^{+}$ions on protein contents were illustrated in Figure 6a. The protein content was increased at the Ag NPs concentration of 25 and $50 \mathrm{ppm}$. A maximum increase in the protein content $(\sim 21 \%)$ was observed in the case of $50 \mathrm{ppm}$ concentration compared to the control. While increasing the concentration to $100 \mathrm{ppm}$, a significant decrease $(\sim 37 \%)$ was recorded compared to the control. However, upon feeding with $\mathrm{Ag}^{+}$ions a maximum reduction in the protein content up to $70 \%$ is observed compared to the control. The increase in the protein content at a certain concentration of NPs defined the optimum dose limit of NPs that stimulate the better growth of plants. However, the decrease in protein content beyond this concentration suggests the toxic effect of Ag NPs, which leached out $\mathrm{Ag}^{+}$ions with the passage of time and consequently behaved similar to the $\mathrm{Ag}^{+}$ions $[42,43]$.
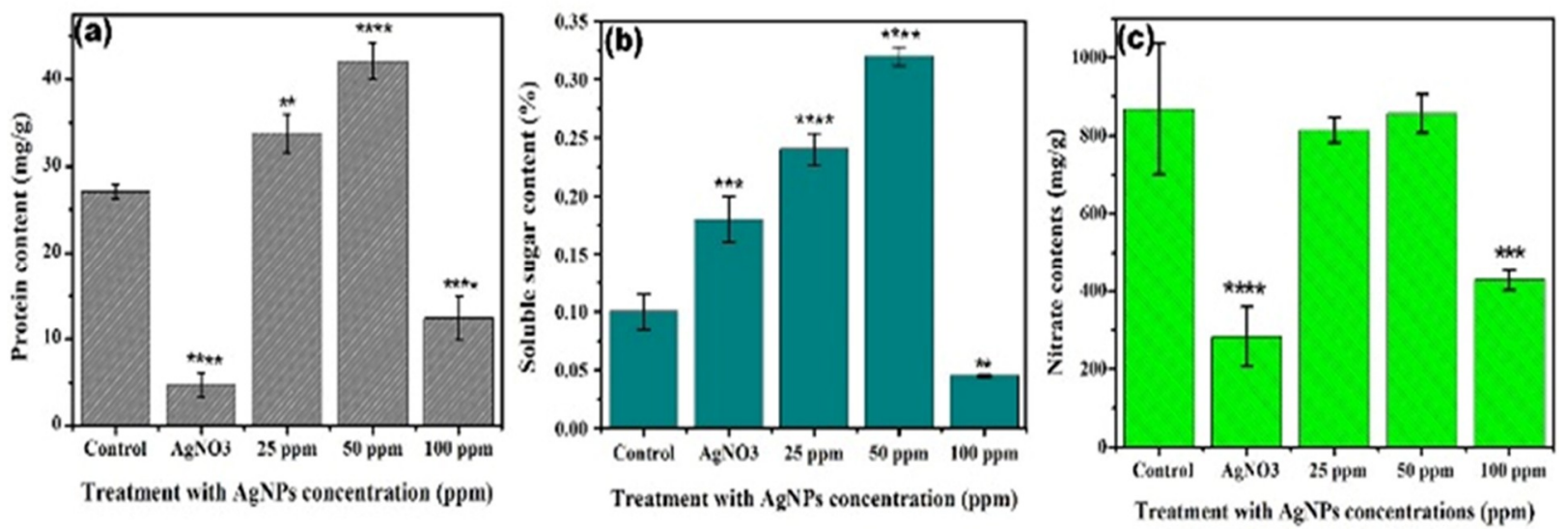

Figure 6. Effect of different concentrations of $\mathrm{Ag} \mathrm{NPs}$ and $\mathrm{AgNO}_{3}$ (a) protein content, (b) soluble sugar content, and (c) nitrate content of lettuce plant. The symbol of ${ }^{* * * * * * * * *}$ show that datasets are significantly different from one another.

The effect of Ag NPs on the sugar content was illustrated in Figure 6b, where an 11\% and $20 \%$ increase is observed in the case of 25 and 50 ppm Ag NPs dose over the control. While, a further increase in the concentration up to $100 \mathrm{ppm}$ caused a $15 \%$ reduction in the sugar content and similarly a decreasing trend is also observed for $\mathrm{Ag}^{+}$ions by a $31 \%$ reduction. The reduction in the carbohydrate content at higher doses may be attributed 
to the toxic level of NPs causing a decline in growth due to the higher release of $\mathrm{Ag}^{+}$ions similar to that of $\mathrm{AgNO}_{3}$ as already reported [43,44].

The effect of $\mathrm{Ag}^{+}$ions and $\mathrm{Ag}$ NPs on the nitrate content is illustrated in Figure 6c. Although, nitrate itself is relatively non-toxic, its metabolites may produce a number of negative effects in plants as in the other living bodies using them [39]. Our results showed that Ag NPs did not cause any significant change in the nitrate content of lettuce plant at 25 and $50 \mathrm{ppm}$ compared to the control. However, at $100 \mathrm{ppm}$, there was a significant decline of $37 \%$ in the nitrate content with regards to the control. Similarly, a sharp decline of $50 \%$ was observed with the $\mathrm{Ag}^{+}$ions treatment compared to the control. Nitrogen is an essential plant element and is related to the cell division and growth, and a treatment with metals could influence their uptake as reported by a previous researcher [45].

The measured variations in protein, sugar, and nitrate contents in response to different concentrations of $\mathrm{Ag}$ NPs and their comparison with $\mathrm{Ag}^{+}$ions and control lettuce confirmed that an optimum dose of metallic ions is required to enhance the growth of plants. As an optimized dose, $50 \mathrm{ppm}$ of Ag NPs had shown significantly increased protein contents by $33 \%$, soluble sugar contents by $69 \%$, and $1 \%$ increase in nitrate contents with regards to the control. However, the excessive infiltration of metallic species to plant bodies release dissolvable ions that disturbed the metabolic systems and denaturized the molecular structure of cellular organelles, ultimately causing disturbance in their proper functionalities [46,47].

To further explore the impact of external metallic contents on plant growth, we analysed the effect of Ag NPs on the total phenolic contents (TPC), scavenging activity, total flavonoid contents (TFC), and total reducing power (TRP), as shown in Figure 7. The scavenging activity was significantly increased in the roots by $10 \%$ and $7 \%$ in response to silver nitrate and $100 \mathrm{ppm} \mathrm{Ag} \mathrm{NPs} \mathrm{as} \mathrm{compared} \mathrm{to} \mathrm{the} \mathrm{control.} \mathrm{However,} \mathrm{no} \mathrm{significant}$ change in the scavenging activity $\mathrm{AgNO}_{3}$ treatment was observed in response to all the concentrations, clearly indicating that $\mathrm{Ag}$ NPs at a higher concentration induced the toxicity in plants leaf, as shown in Figure 7a. The TPC contents in the root were increased by $18 \%$ and $11 \%$, while in leaves it increased up to $8 \%$ and $12 \%$ in response to silver nitrate and $100 \mathrm{ppm}$ Ag NPs compared to the control. While, the level of TPC was increased at 25 and $50 \mathrm{ppm}$ concentration but was not very significant (Figure $7 \mathrm{~b}$ ). In the case of 25 and $50 \mathrm{ppm}$ concentration of NPs, there was no significant difference in the decreased or increased TPC as compared to the control. A 19\% increase in the TRP of roots was observed for silver nitrate and 14\% was observed in the case of $100 \mathrm{ppm}$ of Ag NPs compared to the control. However, the 25 and $50 \mathrm{ppm}$ concentration did not show a significant impact compared to $\mathrm{AgNO}_{3}$ and $100 \mathrm{ppm}$ Ag NPs, as shown in Figure 7c. The TRP of leaves reduced by $18 \%$ and $20 \%$ upon feeding silver nitrate and 25 ppm of Ag NPs, however, no significant difference is observed for a higher concentration of Ag NPs (Figure 7c). Moreover, TFC results were significant in both roots and leaves in response to silver nitrate and 25, 50, and 100 ppm of Ag NPs with regards to the control, as shown in Figure 7d.

Based on the above results, a possible toxicological mechanism of Ag NPs on L. sativa can be inferred. The Ag NPs at a high concentration could accumulate in L. sativa, then cause a decrease in the nitrate uptake and chlorophyll content, and inhibit the ability to photosynthesize. This inhibition may cause a lack of energy (carbohydrate) and slow down the biochemical reactions, as well as the cell division rate. Hence, the growth of L. sativa would be influenced significantly, which highlights the impact of nanomaterials taken by the plants.

For instance, the toxicological effects of $\mathrm{CuO}$ NPs on $B$. nigra seedlings were investigated and the TPC, TAC, and TFC were found to increase up to a certain concentration and then decreased with the increasing NPs concentration [47]. A minor change was observed in TRP, whereas the DPPH-based free radical scavenging activity continuously increased with the increasing NPs concentration. Similarly, it has been observed that ZnO NPs produce stress that act as ethylene production signalling leading towards the biochemical changes in the model plant known as Arabidopsis thaliana (L.) Heynh leaves [48]. 
Although the mechanism of toxic effects of Ag NPs need more evidence, the toxicity of Ag NPs on cells and organisms is partly driven by a release of $\mathrm{Ag}^{+}$ions [49]. This might be the reason for the delayed oxidative stress effects of Ag NPs at higher concentrations as compared to $\mathrm{AgNO}_{3}$ due to the slower release of $\mathrm{Ag}^{+}$ions [50]. In lettuce, the growth and biomass increased on exposure to phytosynthesized $\mathrm{ZnO}$ nanoparticles [51]. Engineered $\mathrm{ZnO}$ nanoparticles increased the fresh/dry weight of leaves and roots in coffee plant [52]. Engineered $\mathrm{ZnO}$ nanoparticles increased the germination and root growth of maize and cabbage [53]. In wheat, engineered $\mathrm{ZnO} N$ Ps increased the growth and reduced the uptake of cadmium [54]. Phytosynthesized $\mathrm{ZnO}$ nanoparticles significantly enhanced germination and shoot/root growth in wheat seedlings [55].

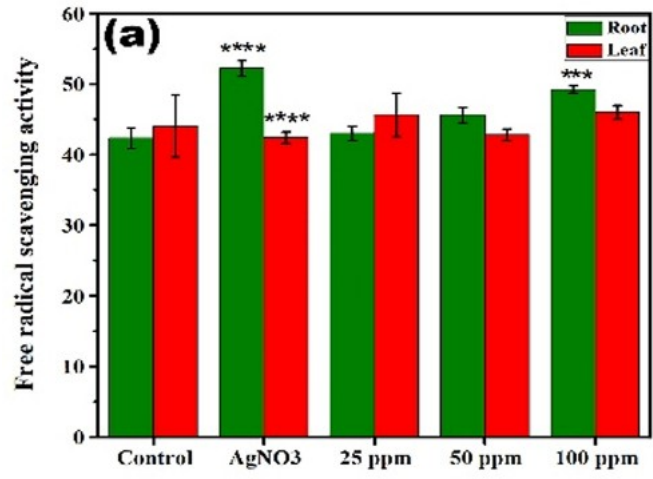

Treatment with AgNPs concentrations (ppm)

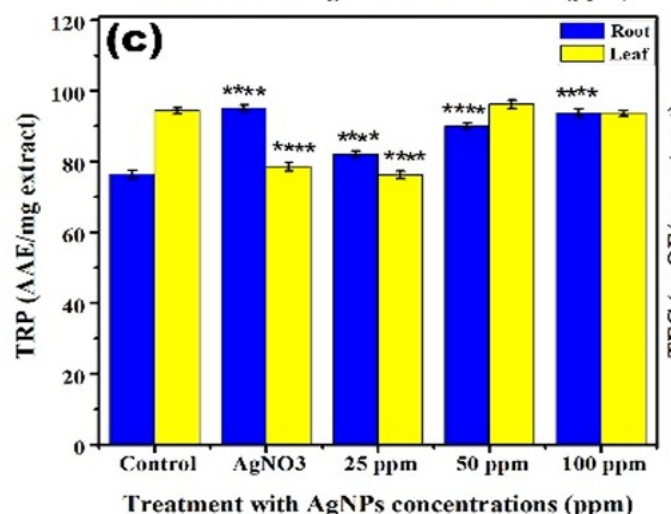

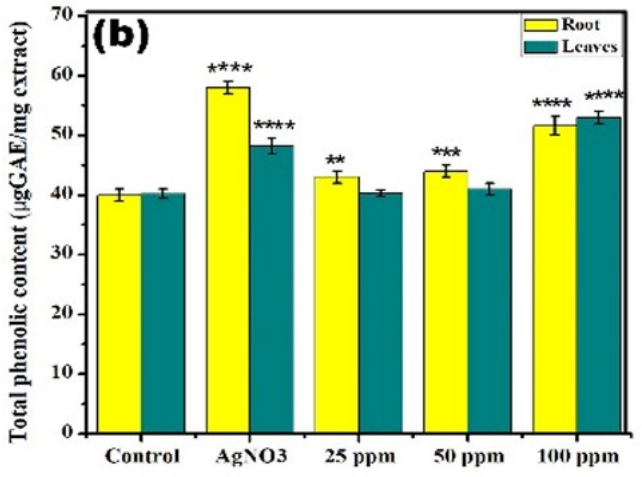

Treatment with AgNPs concentrations (ppm)

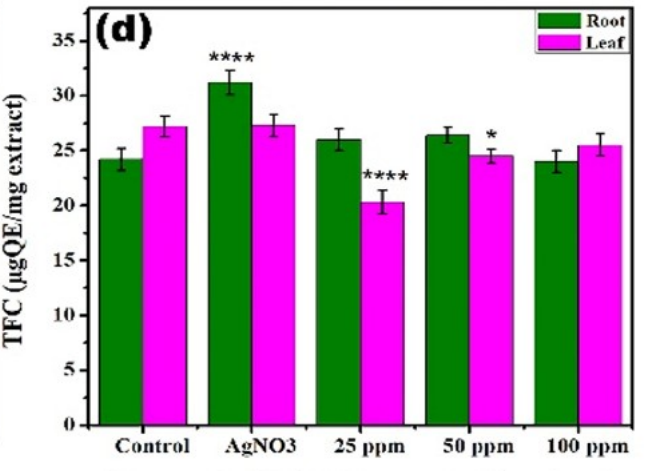

Treatment with AgNPs concentrations (ppm)

Figure 7. Effect of different concentrations of $\mathrm{Ag} \mathrm{NPs}$ and $\mathrm{AgNO}_{3}(1 \mathrm{M})$ on (a) free radical scavenging activity, (b) total reducing power, (c) total phenolic content, and (d) total flavonoid content levels in roots and leaves of lettuce plant. The symbol of ${ }^{* * *}, * * * * * *$ show that datasets are significantly different from one another.

Addressing the matter of the optimized Ag NPs $50 \mathrm{ppm}$ dosage on lettuce had provided a significantly enhanced level of proteins, carbohydrates, and chlorophyll contents, where the protein content has been increased up to $16 \%$, causing an elevation in the chlorophyll content to $25 \%$ which had essentially trigged and boosted the production of Rubisco. The pumped-up rubisco not only initiated the rubisco generated cascade but also provides reactive oxygen species (ROS) generation for photo-protection, photorespiration, photo-tactics, and defensive mechanisms, as shown in Figure 8.

Rubisco dependent photosynthesis, $\mathrm{CO}_{2}$ fixation, and stomatal conductions were also raised, which is clearly depicted by the increase in the chlorophyll content. The carbohydrates content was increased by $11 \%$ whereas sugar, flavonoid, and phenolic contents increased by $12 \%, 12 \%$, and $16 \%$, respectively. On the other hand, a $7 \%$ decrease in the DPPH, $10 \%$ in protein content, and $12 \%$ in TPC were also observed. Ultimately resulting in increased net photosynthesis, osmotic adjustment, enzymatic reaction, signalling, and Rubisco activity by raising the antioxidant activity. 


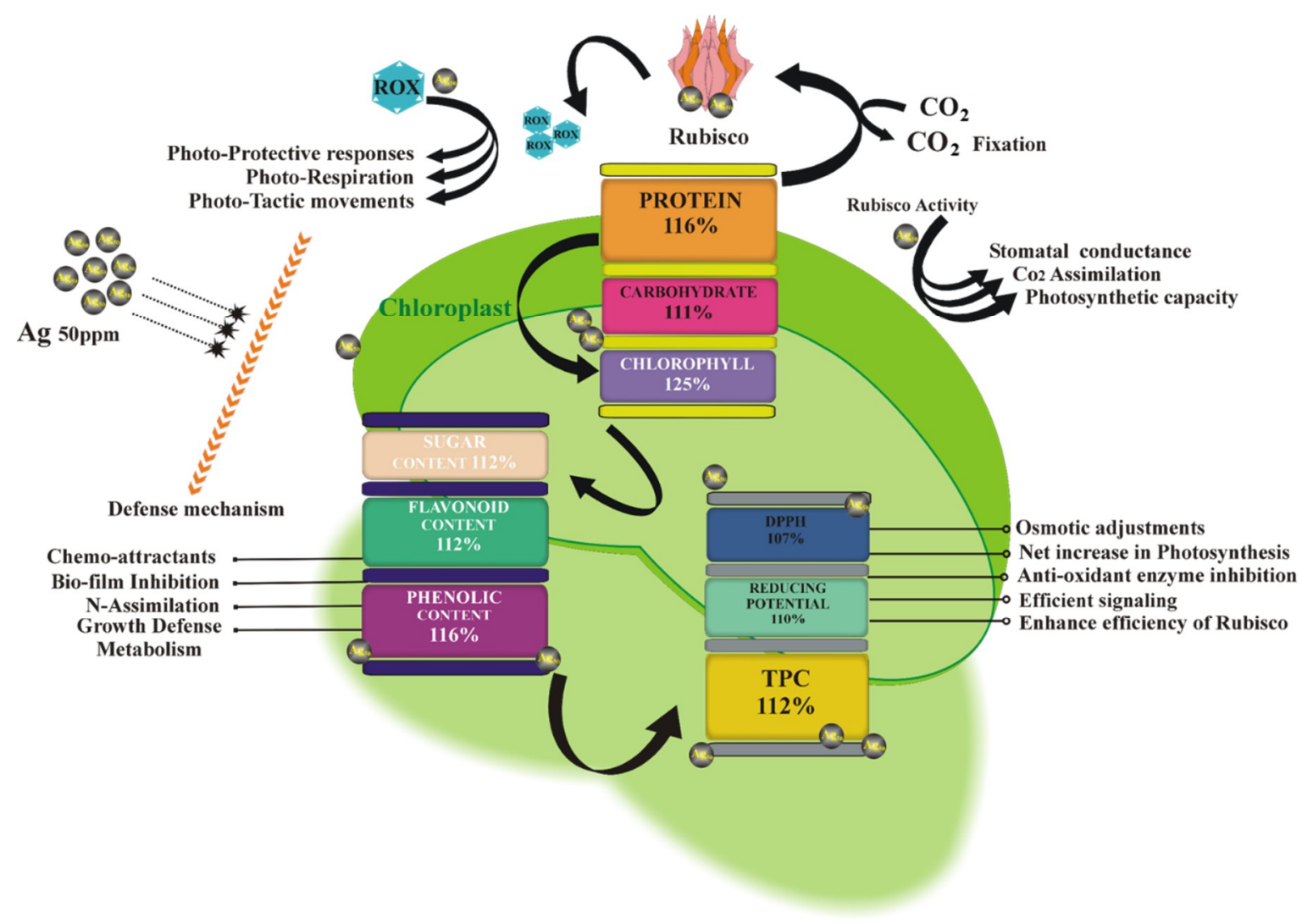

Figure 8. Proposed mechanism of Ag NPs and their effects on the lettuce growth and physiological indicator.

\section{Conclusions}

The present study investigated the phytotoxic effects of $\mathrm{Ag}$ NPs and ions $\left(\mathrm{AgNO}_{3}\right)$ on seedling growth parameters and biochemical properties. The results demonstrated that the interaction of Ag NPs with cells exerted a slight stress condition on the physiological and biochemical properties, as well as the antioxidant activity of the lettuce plant. Among the various concentrations of Ag NPs, the 25 and $50 \mathrm{ppm}$ positively contribute to the production of the protein, soluble sugar, and chlorophyll content compared to the control and $\mathrm{AgNO}_{3}$. While a comparative lower level of total flavonoids, phenolic, DPPH, total antioxidant capacity, and total reducing potential was observed at $100 \mathrm{ppm}$ of Ag NPs. It reflects the better plant growth and reduced toxicity compared to the $\mathrm{AgNO}_{3}$ treated plants. Not surprisingly, the $\mathrm{AgNO}_{3}$ treated plant showed a minimum level of protein, soluble sugar, and chlorophyll content and elevated levels of non-enzymatic antioxidant molecules than the control and Ag NPs treated plant, indicating the increased toxicity of $\mathrm{Ag}^{+}$ions. We believe this mild stress may be beneficial to plants in protecting them against pathogen attacks and disease control and mandates further study in the future.

Supplementary Materials: The following are available online at https:/ / www.mdpi.com/2079-641 2/11/2/225/s1. Figure S1: Schematic presentation of the extraction of a reducing agent from the Fagonia cretica plant for the synthesis of Ag NPs; Figure S2: Hand sowing of lettuce seeds in the seedling tray containing coconut peat; Figure S3: Germination of lettuce seeds in the seedling tray in natural sunlight; Figure S4: Germinating seedlings of lettuce after 7-14 days of sowing; Figure S5: (a) Seedlings of lettuce after being transferred to pots and (b) net pots are placed in containers containing hydroponic nutrients and water; Figure S6: Labeling of lettuce seedlings as five test groups, i.e., control group, 100, 50, 25 mg/L Ag NPs and $\mathrm{AgNO}_{3}$; Figure S7: (a) Lettuce plant after 25 days and ready to harvest. (b) Harvested leaves of lettuce, after 2 weeks; Figure S8: TEM images of Ag NPs taken after their stable suspension for 1 month; Figure S9: Effect of different concentrations of $\mathrm{Ag}$ NPs and $\mathrm{AgNO}_{3}(1 \mathrm{M})$ on the shoot length of the lettuce plant. 
Author Contributions: M.H., N.M., and X.S. conceived and designed the research; M.H., K.M., A.Z., T.T., and G.M. performed the experiments; S.G.H. and S.L. performed the characterization; M.Z. and A.M. did the data analysis; M.H. and K.M. wrote, reviewed, and edited the manuscript. All authors have read and agreed to the published version of the manuscript.

Funding: The authors would like to acknowledge the financial support provided by The Islamia University of Bahawalpur, Pakistan. This work is also supported in part by the Higher Education Commission (HEC) funded National Research Programme for Universities (NRPU) (9458). The authors would like to acknowledge the Vice-Chancellor fellowship scheme at RMIT University, the RMIT Micro Nano Research Facility (MNRF) in the Victorian node of the Australian National Fabrication Facility (ANFF) and the RMIT Microscopy and Microanalysis Facility (RMMF).

Institutional Review Board Statement: Not applicable. This study was approved by the Departmental committee at The Institute of Biochemistry, Biotechnology and Bioinformatics, The Islamia University of Bahawalpur, Pakistan and there is no any work on human/animals.

Informed Consent Statement: It is stated from the all authors that there is no any study on the human/animals.

Data Availability Statement: The additional data regarding the study will be available on request.

Conflicts of Interest: The authors declare no conflict of interest.

\section{References}

1. Libralato, G.; Costa Devoti, A.; Zanella, M.; Sabbioni, E.; Mičetić, I.; Manodori, L.; Pigozzo, A.; Manenti, S.; Groppi, F.; Volpi Ghirardini, A. Phytotoxicity of ionic, micro- and nano-sized iron in three plant species. Ecotoxicol. Environ. Saf. 2016, 123, 81-88. [CrossRef] [PubMed]

2. Alghuthaymi, M.; Abd-Elsalam, K.A.; Paraliker, P.; Rai, M. Mono and hybrid nanomaterials: Novel strategies to manage postharvest diseases. In Multifunctional Hybrid Nanomaterials for Sustainable Agri-Food and Ecosystems; Elsevier: Amsterdam, The Netherlands, 2020.

3. Hasan, M.; Ullah, I.; Zulfiqar, H.; Naeem, K.; Iqbal, A.; Gul, H.; Ashfaq, M.; Mahmood, N. Biological entities as chemical reactors for synthesis of nanomaterials: Progress, challenges and future perspective. Mater. Today Chem. 2018, 8, 13-28. [CrossRef]

4. Qasim, S.; Zafar, A.; Saif, M.S.; Ali, Z.; Nazar, M.; Waqas, M.; Haq, A.U.; Tariq, T.; Hassan, S.G.; Iqbal, F.; et al. Green synthesis of iron oxide nanorods using Withania coagulans extract improved photocatalytic degradation and antimicrobial activity. J. Photochem. Photobiol. B 2020, 204. [CrossRef] [PubMed]

5. Lv, J.; Christie, P.; Zhang, S. Uptake, translocation, and transformation of metal-based nanoparticles in plants: Recent advances and methodological challenges. Environ. Sci. Nano 2019. [CrossRef]

6. Lehner, R.; Weder, C.; Petri-Fink, A.; Rothen-Rutishauser, B. Emergence of nanoplastic in the environment and possible impact on human health. Environ. Sci. Technol. 2019, 53, 1748-1765. [CrossRef]

7. Clark, N.J.; Woznica, W.; Handy, R.D. Dietary bioaccumulation potential of silver nanomaterials compared to silver nitrate in wistar rats using an ex vivo gut sac technique. Ecotoxicol. Environ. Saf. 2020, 200, 110745. [CrossRef] [PubMed]

8. Rico, C.M.; Majumdar, S.; Duarte-Gardea, M.; Peralta-Videa, J.R.; Gardea-Torresdey, J.L. Interaction of nanoparticles with edible plants and their possible implications in the food chain. J. Agric. Food Chem. 2011. [CrossRef] [PubMed]

9. Gupta, S.D.; Agarwal, A.; Pradhan, S. Phytostimulatory effect of silver nanoparticles (AgNPs) on rice seedling growth: An insight from antioxidative enzyme activities and gene expression patterns. Ecotoxicol. Environ. Saf. 2018, 161, 624-633. [CrossRef]

10. Zea, L.; Salama, H.M.H. Effects of silver nanoparticles in some crop plants, Common bean (Phaseolus vulgaris L.) and corn. Int. Res. J. Biotechnol. 2012, 3, 190-197.

11. Li, J.; Hu, J.; Ma, C.; Wang, Y.; Wu, C.; Huang, J.; Xing, B. Uptake, translocation and physiological effects of magnetic iron oxide $\left(\gamma-\mathrm{Fe}_{2} \mathrm{O}_{3}\right)$ nanoparticles in corn (Zea mays L.). Chemosphere 2016, 159, 326-334. [CrossRef] [PubMed]

12. Tombuloglu, H.; Slimani, Y.; Tombuloglu, G.; Almessiere, M.; Baykal, A. Uptake and translocation of magnetite $\left(\mathrm{Fe}_{3} \mathrm{O}_{4}\right)$ nanoparticles and its impact on photosynthetic genes in barley (Hordeum vulgare L.). Chemosphere 2019. [CrossRef] [PubMed]

13. Lv, F.; Hasan, M.; Dang, H.; Hassan, S.G.; Meng, W.; Deng, Y.; Dai, R. Optimized luteolin loaded solid lipid nanoparticle under stress condition for enhanced bioavailability in rat plasma. J. Nanosci. Nanotechnol. 2016. [CrossRef]

14. Azeez, L.; Lateef, A.; Wahab, A.A.; Rufai, M.A.; Salau, A.K.; Ajayi, E.I.O.; Ajayi, M.; Adegbite, M.K.; Adebisi, B. Phytomodulatory effects of silver nanoparticles on Corchorus olitorius: Its antiphytopathogenic and hepatoprotective potentials. Plant Physiol. Biochem. 2019, 136, 109-117. [CrossRef]

15. Yousaf, A.; Zafar, A.; Ali, M.; Bukhary, S.M.; Manzoor, Y.; Tariq, T.; Saeed, A.; Akram, M.; Bukhari, F.; Abdullah, M.; et al. Intrinsic Bio-Enhancer Entities of Fagonia cretica for Synthesis of Silver nanoparticles involves anti-urease, anti-oxidant and anti-tyosinase activity. Adv. Biosci. Biotechnol. 2019. [CrossRef]

16. Zhang, C.L.; Jiang, H.S.; Gu, S.P.; Zhou, X.H.; Lu, Z.W.; Kang, X.H.; Yin, L.; Huang, J. Combination analysis of the physiology and transcriptome provides insights into the mechanism of silver nanoparticles phytotoxicity. Environ. Pollut. 2019. [CrossRef] 
17. Mustafa, G.; Hasan, M.; Yamaguchi, H.; Hitachi, K.; Tsuchida, K.; Komatsu, S. A comparative proteomic analysis of engineered and bio synthesized silver nanoparticles on soybean seedlings. J. Proteom. 2020. [CrossRef]

18. Zulfiqar, H.; Zafar, A.; Rasheed, M.N.; Ali, Z.; Mehmood, K.; Mazher, A.; Hasan, M.; Mahmood, N. Synthesis of silver nanoparticles using: Fagonia cretica and their antimicrobial activities. Nanoscale Adv. 2019. [CrossRef]

19. Li, W.Q.; Qing, T.; Li, C.C.; Li, F.; Ge, F.; Fei, J.J.; Peijnenburg, W.J.G.M. Integration of subcellular partitioning and chemical forms to understand silver nanoparticles toxicity to lettuce (Lactuca sativa L.) under different exposure pathways. Chemosphere 2020, 258, 127349. [CrossRef] [PubMed]

20. De Paiva Pinheiro, S.K.; De Medeiros Chaves, M.; Rangel Miguel, T.B.A.; De Freitas Barros, F.C.; Farias, C.P.; Ferreira, O.P.; De Castro Miguel, E. Toxic effects of silver nanoparticles on the germination and root development of lettuce (Lactuca sativa). Aust. J. Bot. 2020, 68, 127-136. [CrossRef]

21. Ernst, O.; Zor, T. Linearization of the Bradford protein assay. J. Vis. Exp. 2010, 38, 1918. [CrossRef] [PubMed]

22. Burman, U.; Kumar, P. Plant Response to Engineered Nanoparticles. In Nanomaterials in Plants, Algae, and Microorganisms; Academic Press: Cambridge, MA, USA, 2018. [CrossRef]

23. Munawar, T.; Yasmeen, S.; Hasan, M.; Mahmood, K.; Hussain, A.; Ali, A.; Arshad, M.I.; Iqbal, F. Novel tri-phase heterostructured $\mathrm{ZnO}-\mathrm{Yb} 2 \mathrm{O} 3-\mathrm{Pr} 2 \mathrm{O} 3$ nanocomposite; structural, optical, photocatalytic and antibacterial studies. Ceram. Int. 2020, 46, 11101-11114. [CrossRef]

24. Mukhtar, F.; Tauseef Munawar, T.; Nadeem, M.S.; Hasan, M.; Hussain, F.; Nawaz, A.; Faisal, I. Multi metal oxide NiO-Fe 2 O 3-CdO nanocomposite-synthesis, photocatalytic and antibacterial properties. Appl. Phys. A 2020, 126, 588. [CrossRef]

25. Hasan, Z.A.; Shahzadi, I.; Luo, F.; Hassan, S.G.; Tariq, T.; Zehra, S.; Munawar, T.; Iqbal, F.; Shu, X. Fractionation of biomolecules in withania coagulans extract for bioreductive nanoparticle synthesis, antifungal and biofilm activity. Molecules 2020, 25, 3478. [CrossRef] [PubMed]

26. Hasan, M.; Rafique, S.; Zafar, A.; Loomba, S.; Khan, R.; Hassan, S.G.; Khan, M.W.; Zahra, S.; Zia, M.; Mustafa, G.; et al. Physiological and anti-oxidative response of biologically and chemically synthesized iron oxide: Zea mays a case study. Heliyon 2020, 6. [CrossRef] [PubMed]

27. Hasan, M.; Altaf, M.; Zafar, A.; Hassan, S.G.; Ali, Z.; Mustafa, G.; Munawar, T.; Saif, M.S.; Tariq, T.; Iqbal, F.; et al. Bioinspired synthesis of zinc oxide nano-flowers: A surface enhanced antibacterial and harvesting efficiency. Mater. Sci. Eng. C 2021, 119. [CrossRef]

28. Akbar, S.; Haleem, K.S.; Tauseef, I.; Rehman, W.; Ali, N.; Hasan, M. Raphanus sativus mediated synthesis, characterization and biological evaluation of zinc oxide nanoparticles. Nanosci. Nanotechnol. Lett. 2018, 9, 2005-2012. [CrossRef]

29. Chow, P.S.; Landhäusser, S.M. A method for routine measurements of total sugar and starch content in woody plant tissues. Tree Physiol. 2004, 24, 1129-1136. [CrossRef] [PubMed]

30. Spielman-Sun, E.; Avellan, A.; Bland, G.D.; Tappero, R.V.; Acerbo, A.S.; Unrine, J.M.; Giraldo, J.P.; Lowry, G.V. Nanoparticle surface charge influences translocation and leaf distribution in vascular plants with contrasting anatomy. Environ. Sci. Nano 2019. [CrossRef]

31. Hasan, M.; Iqbal, J.; Awan, U.; Saeed, Y.; Ranran, Y.; Liang, Y.; Dai, R.; Deng, Y. Mechanistic study of silver nanoparticle's synthesis by Dragon's blood resin ethanol extract and antiradiation activity. J. Nanosci. Nanotechnol. 2015, 15, 1320-1326. [CrossRef] [PubMed]

32. Hasan, M.; Teng, Z.; Iqbal, J.; Awan, U.; Meng, S.; Dai, R.; Qing, H.; Deng, Y. Assessment of bioreducing and stabilizing potential of dragon's blood (dracaena cochinchinensis, Lour. S. C. Chen) resin extract in synthesis of silver nanoparticles. Nanosci. Nanotechnol. Lett. 2013, 5, 780-784. [CrossRef]

33. Iqbal, M.; Raja, N.I.; Mashwani, Z.-U.-R.; Hussain, M.; Ejaz, M.; Yasmeen, F. Effect of silver nanoparticles on growth of wheat under heat stress. Iran. J. Sci. Technol. Trans. A Sci. 2019, 43, 387-395. [CrossRef]

34. Cox, A.; Venkatachalam, P.; Sahi, S.; Sharma, N. Silver and titanium dioxide nanoparticle toxicity in plants: A review of current research. Plant Physiol. Biochem. 2016, 107, 147-163. [CrossRef]

35. Harshiny, M.; Matheswaran, M.; Arthanareeswaran, G.; Kumaran, S.; Rajasree, S. Enhancement of antibacterial properties of silver nanoparticles-ceftriaxone conjugate through Mukia maderaspatana leaf extract mediated synthesis. Ecotoxicol. Environ. Saf. 2015, 121, 135-141. [CrossRef] [PubMed]

36. Yasur, J.; Rani, P.U. Environmental effects of nanosilver: Impact on castor seed germination, seedling growth, and plant physiology. Environ. Sci. Pollut. Res. 2013. [CrossRef]

37. Monreal, C.M.; DeRosa, M.; Mallubhotla, S.C.; Bindraban, P.S.; Dimkpa, C. Nanotechnologies for increasing the crop use efficiency of fertilizer-micronutrients. Biol. Fertil. Soils 2016. [CrossRef]

38. Shang, Y.; Hasan, K.; Ahammed, G.J.; Li, M.; Yin, H.; Zhou, J. Applications of nanotechnology in plant growth and crop protection: A review. Molecules 2019. [CrossRef] [PubMed]

39. Shah, S.H.; Houborg, R.; McCabe, M.F. Response of chlorophyll, carotenoid and SPAD-502 measurement to salinity and nu-trient stress in wheat (Triticum aestivum L.). Agronomy 2017, 7, 61. [CrossRef]

40. Antony, J.J.; Sivalingam, P.; Chen, B. Toxicological effects of silver nanoparticles. Environ. Toxicol. Pharmacol. 2015, 40, 729-732. [CrossRef]

41. Faisal, M.; Saquib, Q.; Alatar, A.A.; Al-Khedhairy, A.A. Phytotoxicity of Nanoparticles; Springer: Berlin, Germany, 2018. [CrossRef] 
42. Meyer, J.N.; Lord, C.A.; Yang, X.Y.; Turner, E.A.; Badireddy, A.R.; Marinakos, S.M.; Chilkoti, A.; Wiesner, M.R.; Auffan, M. Intracellular uptake and associated toxicity of silver nanoparticles in Caenorhabditis elegans. Aquat. Toxicol. 2010. [CrossRef]

43. Jiang, H.-S.; Li, M.; Chang, F.-Y.; Li, W.; Yin, L.-Y. Physiological analysis of silver nanoparticles and $\mathrm{AgNO}_{3}$ toxicity to Spirodela polyrhiza. Environ. Toxicol. Chem. 2012, 31, 1880-1886. [CrossRef]

44. Mustafa, G.; Komatsu, S. Toxicity of heavy metals and metal-containing nanoparticles on plants. Biochim. Biophys. Acta 2016. [CrossRef]

45. Adrees, M.; Ali, S.; Rizwan, M.; Zia-Ur-Rehman, M.; Ibrahim, M.; Abbas, F.; Farid, M.; Qayyum, M.F.; Irshad, M.K. Mechanisms of silicon-mediated alleviation of heavy metal toxicity in plants: A review. Ecotoxicol. Environ. Saf. 2015, 119, 186-197. [CrossRef] [PubMed]

46. Singh, S.; Parihar, P.; Singh, R.; Singh, V.P.; Prasad, S.M. Heavy metal tolerance in plants: Role of transcriptomics, proteomics, metabolomics, and ionomics. Front. Plant Sci. 2016. [CrossRef]

47. Ko, K.-S.; Koh, D.-C.; Kong, I.C. Evaluation of the effects of nanoparticle mixtures on brassica seed germination and bacterial bioluminescence activity based on the theory of probability. Nanomaterials 2017, 7, 344. [CrossRef] [PubMed]

48. Suman, T.Y.; Rajasree, S.R.R.; Kirubagaran, R. Evaluation of zinc oxide nanoparticles toxicity on marine algae chlorella vulgaris through flow cytometric, cytotoxicity and oxidative stress analysis. Ecotoxicol. Environ. Saf. 2015. [CrossRef] [PubMed]

49. De Matteis, V.; Rinaldi, R. Toxicity Assessment in the Nanoparticle Era. In Advances in Experimental Medicine and Biology; Springer: Berlin, Germany, 2018. [CrossRef]

50. Wang, J.; Asbach, C.; Fissan, H.; Hülser, T.; Kuhlbusch, T.A.J.; Thompson, D.; Pui, D.Y.H. How can nanobiotechnology oversight advance science and industry: Examples from environmental, health, and safety studies of nanoparticles (nano-EHS). $J$. Nanoparticle Res. 2011. [CrossRef]

51. Xu, J.; Luo, X.; Wang, Y.; Feng, Y. Evaluation of zinc oxide nanoparticles on lettuce (Lactuca sativa L.) growth and soil bacterial community. Environ. Sci. Pollut. Res. 2018, 25, 6026-6035. [CrossRef]

52. Rossi, L.; Fedenia, L.N.; Sharifan, H.; Ma, X.; Lombardini, L. Effects of foliar application of zinc sulfate and zinc nanoparticles in coffee (Coffea arabica L.) plants. Plant Physiol. Biochem. 2019, 135, 160-166. [CrossRef]

53. Pokhrel, L.R.; Dubey, B. Evaluation of developmental responses of two crop plants exposed to silver and zinc oxide nanoparticles. Sci. Total. Environ. 2013, 453, 321-332. [CrossRef]

54. Rizwan, M.; Ali, S.; Rehman, M.Z.U.; Adrees, M.; Arshad, M.; Qayyum, M.F.; Ali, L.; Hussain, A.; Chatha, S.A.S.; Imran, M. Alleviation of cadmium accumulation in maize (Zea mays L.) by foliar spray of zinc oxide nanoparticles and biochar to contaminated soil. Environ. Pollut. 2019, 248, 358-367. [CrossRef]

55. Singh, A.; Singh, N.; Hussain, I.; Singh, H.; Yadav, V.; Singh, S. Green synthesis of nano zinc oxide and evaluation of its impact on germination and metabolic activity of Solanum lycopersicum. J. Biotechnol. 2016, 233, 84-94. [CrossRef] [PubMed] 